Check for updates

Cite this: Phys. Chem. Chem. Phys., 2020, 22, 2660

Received 20th June 2019, Accepted 31st July 2019

DOI: $10.1039 / \mathrm{c} 9 \mathrm{cp} 03483 \mathrm{~h}$

rsc.li/pccp

\section{Resolving structures of transition metal complex reaction intermediates with femtosecond EXAFS $\uparrow$}

\author{
Alexander Britz, (D)*ab Baxter Abraham, ${ }^{\text {bc }}$ Elisa Biasin, ${ }^{a}$ Tim Brandt van Driel, ${ }^{\mathrm{b}}$ \\ Alessandro Gallo, de Angel T. Garcia-Esparza, (D) c James Glownia, ${ }^{\mathrm{b}}$ \\ Anton Loukianov, ${ }^{\mathrm{b}}$ Silke Nelson, ${ }^{\mathrm{b}}$ Marco Reinhard, ${ }^{\mathrm{a}}$ Dimosthenis Sokaras ${ }^{* \mathrm{c}}$ and \\ Roberto Alonso-Mori*b
}

\begin{abstract}
Femtosecond-resolved Extended X-ray Absorption Fine Structure (EXAFS) measurements of solvated transition metal complexes are successfully implemented at the X-ray Free Electron Laser LCLS. Benchmark experiments on $\left[\mathrm{Fe}(\text { terpy })_{2}\right]^{2+}$ in solution show a signal-to-noise ratio on the order of 500 , comparable to typical 100 ps-resolution synchrotron measurements. In the few femtoseconds after photoexcitation, we observe the EXAFS fingerprints of a short-lived ( 100 fs) intermediate as well as those of a vibrationally hot long-lived ( $\sim$ ns) excited state.
\end{abstract}

\section{Introduction}

Transition Metals are ubiquitous in biological systems, e.g. Fe in the Heme group in Myoglobin ${ }^{1}$ and the Mn cluster in Photosystem II. $^{2}$ Furthermore, they play essential roles in catalytic applications; Transition Metal (TM) complexes are used as photosensitizers for hydrogen evolution, ${ }^{3}$ for conversion of solar to electric energy ${ }^{4}$ and TM oxide nanoparticles are exploited as photocatalysts. ${ }^{5,6}$ Hard X-ray absorption spectroscopy (XAS) is ideally suited to investigate such TM centers due to its element specificity and sensitivity to changes in the geometric and electronic structures. The X-ray Absorption Near Edge Structure (XANES), i.e. the region around the absorption edge typically up to a few tens of eV above the edge, is rich in electronic structure information (e.g. oxidation state or valence orbital occupation) through transitions of a core electron to unoccupied valence states. ${ }^{7,8}$ Furthermore, the shape of the absorption edge can be analyzed to obtain geometric structure information. ${ }^{9}$ Analyzing the Extended X-ray Absorption Fine Structure (EXAFS), a wide region from tens of eV to several hundreds of $\mathrm{eV}$ above the absorption edge, is very beneficial,

\footnotetext{
${ }^{a}$ Stanford PULSE Institute, SLAC National Accelerator Laboratory, Menlo Park, CA 94025, USA. E-mail: abritz@slac.stanford.edu

${ }^{b}$ Linac Coherent Light Source, SLAC National Accelerator Laboratory, Menlo Park, CA 94025, USA. E-mail: robertoa@slac.stanford.edu

${ }^{c}$ Stanford Synchrotron Radiation Lightsource, SLAC National Accelerator Laboratory, Menlo Park, CA 94025, USA. E-mail: dsokaras@slac.stanford.edu

${ }^{d}$ SUNCAT Center for Interface Science and Catalysis, Department of Chemical Engineering, Stanford University, Stanford, CA 94305, USA

${ }^{e}$ SUNCAT Center for Interface Science and Catalysis, SLAC National Accelerator Laboratory, Menlo Park, CA 94025, USA

$\dagger$ Electronic supplementary information (ESI) available. See DOI: 10.1039/c9cp03483h
}

as it is dominated by the local geometry in the close vicinity of the absorbing atom. EXAFS spectra can be very well understood and modeled in a single photo-electron picture, which is generated in the X-ray absorption process and scatters of the neighboring atoms. The modulations in the X-ray absorption probability are due to interferences of this photo-electron wave with itself and can be analyzed by Fourier transformation to produce pseudo-radial distribution functions of the local atomic surroundings. ${ }^{10-12}$

X-ray Free Electron Lasers (XFELs) provide intense and ultrashort X-ray pulses, ${ }^{13}$ which ultimately enable the measurement of ultrafast XAS with a temporal resolution of $<100 \mathrm{fs}$, limited among other things (e.g. laser pulse duration, sample thickness, timing jitter) by the pulse duration of the X-rays. Furthermore, the intense XFEL pulses can be used to obtain XANES measurements free of radiation damage (which is induced e.g. by radical diffusion) ${ }^{14}$ similar to diffract-beforedestroy crystallography experiments. ${ }^{15}$ XFEL based XANES was first used at the Linac Coherent Light Source (LCLS) to study the ultrafast spin switching in the model systems $\left[\mathrm{Fe}(\mathrm{bpy})_{3}\right]^{2+16}$ and $\left[\mathrm{Fe}(\mathrm{phen})_{2}(\mathrm{NCS})_{2}\right] \cdot{ }^{17}$ Since then, femtosecond XANES has found numerous applications: the photoactivation and the subsequent ultrafast structural and electronic dynamics of the active sites of several biomolecules have been investigated, including carbonmonoxy myoglobin, ${ }^{18}$ vitamin B12, ${ }^{19,20}$ and in model Ni-porphyrins. ${ }^{21}$ Next to TM complex systems, fs timeresolved XAS has been applied to condensed matter charge carrier dynamics; at the SACLA XFEL, the charge-carrier dynamics of anatase $\mathrm{TiO}_{2}$ nanoparticles in an aqueous solution were investigated via Ti K-edge XANES, which revealed trapping of the conduction band electrons in $\sim 100 \mathrm{fs}^{6}{ }^{6}$ The energy range of the XANES can be increased in order to enhance the 
structural sensitivity. For example, XAS scanned up to $\sim 110 \mathrm{eV}$ above the Fe K-edge in cytochrome $c$ has been exploited to capture the low energy portion of the EXAFS region, which facilitated tracking the Fe-S bond distance in the Fe-methionine dissociation and recombination. ${ }^{22}$ Despite the success of these experiments, analyzing and interpreting XANES spectra remains challenging due to the tangled electronic and geometric structure information contained in the spectra. Time-resolved X-ray diffuse scattering (XDS), a complementary technique to study the structural dynamics of solvated molecular systems, suffers from another disadvantage. Since the scattering signal consists, due to the lack of element specificity, of contributions from all atoms in the sample, disentangling the numerous inter- and intra-nuclear degrees of freedom involved in photoinduced structural dynamics can be troublesome. ${ }^{23-26}$

Time-resolved EXAFS with $\sim 70$ ps resolution is to date measured routinely at synchrotrons with numerous applications to investigate a broad range of materials. While the aforementioned XANES measurements of photoexcited $\mathrm{TiO}_{2}$ revealed the timescale of the electron trapping, the extension to the EXAFS regime to study $\mathrm{ZnO}$ nanoparticles allowed the precise characterization of the hole trapping site as a singly charged oxygen vacancies. ${ }^{5}$ A further advantage of time-resolved EXAFS is the high accuracy - on the order of 1 picometer - in resolving the TM-ligand bond distances and the changes therein, ${ }^{27}$ as well as the sensitivity in resolving asymmetries in the first coordination shell around the TM. ${ }^{28-32}$ Extending EXAFS of weakly concentrated solvated samples to the femtosecond regime with beam slicing at synchrotrons ${ }^{33}$ or tabletop plasma source ${ }^{34}$ is not viable due to the low photon flux and/or limited photon energy tunability of these source. Measuring femtosecond resolved EXAFS at XFELs is challenging due several reasons: (i) the extremely large pulse-to-pulse fluctuations due to the Self-Amplified Spontaneous Emission (SASE) process require a systematic and rigorous normalization and (ii) scanning the incident X-ray energy over a broad range is technically challenging, as it either requires a very accurate scanning of the long $(\sim 100 \mathrm{~m})$ undulator gaps, or, in the case of LCLS with fixed gap undulators, a continuous modulation of the accelerator electron energy. Recently, a first steady-state EXAFS spectrum acquired at LCLS has been published. ${ }^{35}$

Here, we present the extension of EXAFS to the femtosecond regime. We show full range time resolved EXAFS spectra up to $\sim 500 \mathrm{eV}$ above the absorption edge $\left(k \simeq 12 \AA^{-1}\right)$ and demonstrate the possibility of extracting structural information of $\sim 100$ fs lived intermediate states in the relaxation pathways of photoactivated TM complexes.

\section{Experimental methodology to measure EXAFS at LCLS}

Ultrafast XAS of Fe complexes in solution was measured at the X-ray Pump Probe instrument (XPP) ${ }^{36}$ of the Linac Coherent Light Source (LCLS). The incident X-ray beam with a bandwidth of $\sim 30 \mathrm{eV}$ and pulse energy of typically $2-3 \mathrm{~mJ}$ was monochromatized to $\Delta E / E \simeq 1.4 \times 10^{-4}$ with a channel cut $\mathrm{Si}(111)$ monochromator, ${ }^{37}$ which effectively reduces the pulse energy by two orders of magnitude. The incident X-ray energy was scanned through a combination of accelerator electron beam variation and monochromator adjustment. The X-ray beam was focused to $\sim 25 \mu \mathrm{m}$ at the sample using a set of Be compound refractive lenses. To compensate for the change of refractive index of Be while scanning the incident $\mathrm{X}$-ray energy, and thus the change in focal position with respect to the lens, the lens stack position along the X-ray propagation direction was adjusted according to the X-ray energy. The sample, a $20 \mathrm{mM}$ solution of $\left[\mathrm{Fe}(\text { terpy })_{2}\right]^{2+}$ (where terpy is $2,2^{\prime}: 6^{\prime}, 2^{\prime \prime}$ terpyridine, see Fig. 3a) in $\mathrm{H}_{2} \mathrm{O}$, was contained in a free-flowing round liquid jet with $50 \mu \mathrm{m}$ thickness. The X-ray absorption signal was measured in total fluorescence yield (TFY) mode with an ePix100 detector with $768 \times 704$ pixels of $50 \times 50 \mu \mathrm{m}^{2} \mathrm{size}^{38}$ mounted in the X-ray beam propagation plane and perpendicular to the beam direction in order to minimize the collection of elastic scattering. A circular region of interest (ROI) in the center of the ePix100 detector was selected and integrated for the TFY signal. The intensity of the incident X-ray beam $\left(I_{0}\right)$ was measured by collecting the diffuse scattering of the solvent $\left(\mathrm{H}_{2} \mathrm{O}\right)$ using a CSPAD $2.3 \mathrm{M},{ }^{38}$ with the advantage of a single-shot normalization to fluctuations in the jet thickness as well the incoming X-ray intensity. An ROI to select the water ring was integrated as $I_{0}$. Dividing the TFY by $I_{0}$ yields the normalization corrected XAS signal (Fig. 1). To measure time-resolved XAS, the sample was excited with visible laser pulses at a wavelength of $500 \mathrm{~nm}$ and a pulse energy of $12 \mu \mathrm{J}$, which were focused to a $150 \mu \mathrm{m}$ (fwhm) spot at the sample position. Arbitrary data acquisition patterns of laser-excited and ground state (no visible excitation laser) can be chosen, and 2 out of 9 X-ray pulses were used to measure the ground state, while 7 out 9 pulses were used for the laser-excited XAS measurement.

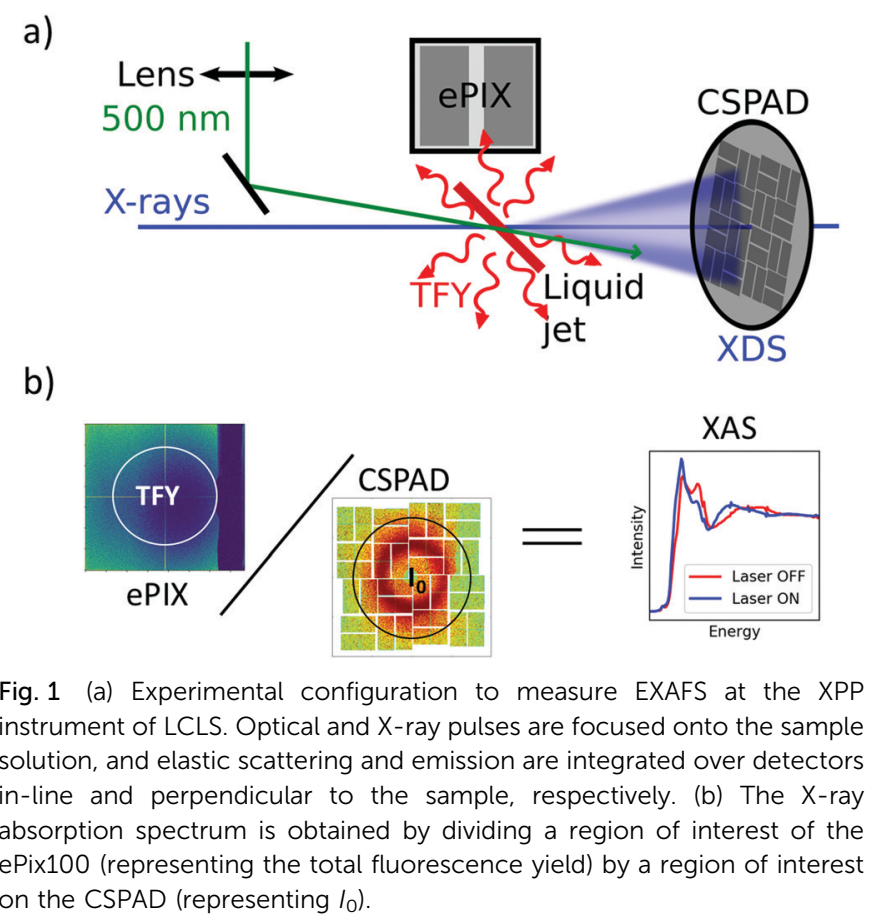




\section{Benchmark picosecond EXAFS measurements of transition metal complexes}

As a benchmark test, EXAFS spectra of a $20 \mathrm{mM}$ solution $\left[\mathrm{Fe}(\text { terpy })_{2}\right]^{2+}$ in $\mathrm{H}_{2} \mathrm{O}$ were acquired $10 \mathrm{ps}$ after $500 \mathrm{~nm}$ excitation in the metal-to-ligand charge transfer (MLCT) bands. The photophysical processes (see Fig. $3 \mathrm{~b}$ ) of $\left[\mathrm{Fe}(\text { terpy })_{2}\right]^{2+}$ are expected to be very similar to those of other low spin (LS) $\mathrm{Fe}(\mathrm{II})$ complexes such as $\left[\mathrm{Fe}(\mathrm{bpy})_{3}\right]^{2+} \cdot{ }^{30}$ Optical excitation to the MLCT states is followed by ultrafast relaxation to a longer-lived high-spin (HS) ${ }^{5} \mathrm{~T}_{2}$ state. The initial MLCT lifetime is on the order of $\sim 100 \mathrm{fs}$, and the relaxation cascade involves the crossing of a metal-centered (MC) intermediate spin (IS) ${ }^{3} \mathrm{~T}$ state with a similar lifetime of $\sim 100 \mathrm{fs}$, the ground state recovery time from the final HS state is comparably long ( $\gg 100 \mathrm{ps}) \cdot{ }^{39}$ In the LS ground state of (quasi) octahedral Fe(II) complexes, all six 3d electrons occupy the non-bonding $t_{2 g}$ orbitals, leaving the antibonding $\mathrm{e}_{\mathrm{g}}{ }^{*}$ orbitals empty. In the IS and HS excited states, the $\mathrm{e}_{\mathrm{g}}{ }^{*}$ orbitals are singly and doubly occupied, respectively. In the case of $\left[\mathrm{Fe}(\text { terpy })_{2}\right]^{2+}$, the long-lived $\left(\sim 2.6 \mathrm{~ns}\right.$ in $\left.\mathrm{H}_{2} \mathrm{O}\right) \mathrm{HS}$ state has been extensively studied with hard X-ray spectroscopy, including EXAFS, and the $\mathrm{Fe}-\mathrm{N}$ bond elongation was found to be $\sim 0.2 \AA{ }^{28-30}$ This bond elongation of $\sim 0.2 \AA$ is typical for $\mathrm{Fe}(\mathrm{II})$ complexes during the LS-HS transition and due to the double occupation of the $\mathrm{e}_{\mathrm{g}}{ }^{*}$ orbitals. A single change in the $\mathrm{e}_{\mathrm{g}}{ }^{*}$ configuration, as is the case for the triplet IS state in $\mathrm{Fe}(\mathrm{II})$ systems, is expected to result in a smaller average bond length change on the order of $\sim 0.1 \AA$. Similarly, an average metalligand bond elongation of $\sim 0.1 \AA$ has been observed for the doublet-quartet transition in $\left[\mathrm{Co}(\text { terpy })_{2}\right]^{2+23}$

The XAS spectrum, with and without laser excitation (Fig. 2) was removed from artifacts (see ESI $\dagger$ for details on the deglitching procedure). The measured energy range allows the analysis of the

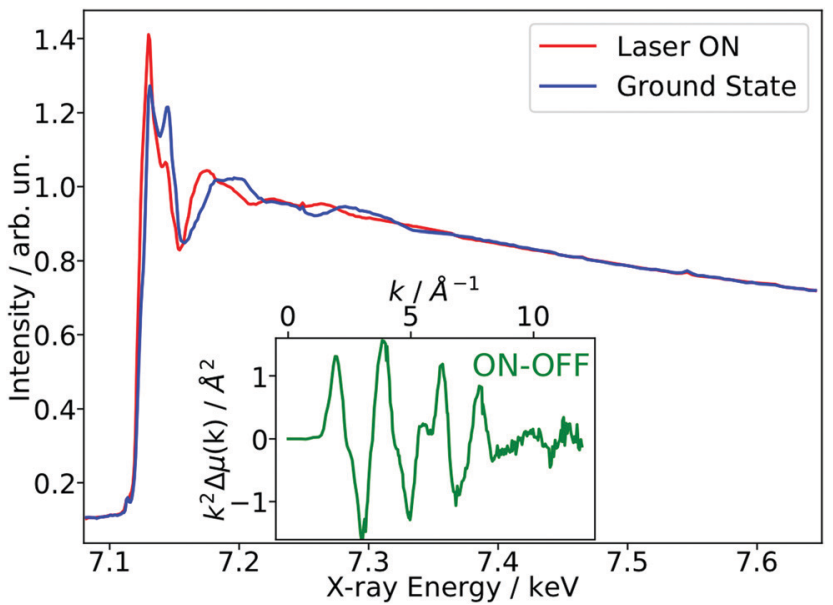

Fig. 2 X-ray absorption spectra of a $20 \mathrm{mM}$ aqueous solution of $\left[\mathrm{Fe}(\text { terpy })_{2}\right]^{2+}$ in the ground state and $10 \mathrm{ps}$ after $500 \mathrm{~nm}$ excitation (Laser $\mathrm{ON}$ ). In the inset, the transient difference in photoelectron wavevector $k$-space, weighted by $k^{2}$, shows clear light-induced changes over the whole spectral range up to $\sim 12 \AA^{-1}$.
EXAFS spectrum up to a photoelectron wavevector $k$ of $\sim 11.9 \AA^{-1}$ and optically induced transient differences are visible over the whole spectral range (see inset on Fig. 2). The total acquisition time of the data shown in Fig. 2 was $\sim 3.5$ h, with $\sim 250$ energy points equidistant in $k$-space. The laser excitation fraction is determined to be $f=76 \%$ by comparing the intensity of the transient difference (normalized to the K-edge amplitude) of $\left[\mathrm{Fe}(\text { terpy })_{2}\right]^{2+}$ to the published synchrotron measurements, in which complementary X-ray emission spectroscopy (XES) measurements were used to precisely determine the excited state fraction. ${ }^{30}$ The laser excited spectrum $\mu_{\text {LON }}$ contains contributions from both ground and excited state, as not all molecules are turned over to the HS state by the optical laser. As the excited state fraction $f$ is known, the ES absorption spectrum $\mu_{\mathrm{ES}}$ is obtained by removing the contribution from the ground state absorption spectrum $\mu_{\mathrm{GS}}\left(=\mu_{\mathrm{LOFF}}\right) v_{i a^{31}}$

$$
\mu_{\mathrm{ES}}=\mu_{\mathrm{LOFF}}+(1 / f) \times\left(\mu_{\mathrm{LON}}-\mu_{\mathrm{LOFF}}\right)
$$

The EXAFS spectra $\mu_{\mathrm{GS}}$ and $\mu_{\mathrm{ES}}$, were then analyzed with the Demeter 0.9.26 software package, which includes ATHENA for background subtraction, FEFF6 for the EXAFS simulation and ARTEMIS for the final fit. ${ }^{40}$ Fig. $3 \mathrm{c}$ shows the spectra after removing the atomic background in ATHENA and translating to photoelectron wavevector $k$-space. The EXAFS spectra of the LS and HS states were further modeled with FEFF6 using structures obtained by density functional theory (DFT) calculations of both states from literature. ${ }^{41}$ The modeled spectra were then fitted to the experimental data in the Fourier transform $R$-space (Fig. 3d). Additional details on the EXAFS fitting procedure can be found in the ESI. $\dagger$ The EXAFS fit results in axial and equatorial Fe-N bond lengths $R_{\mathrm{Nax}}=1.86 \pm 0.03 \AA$ and $R_{\mathrm{Neq}}=$ $1.96 \pm 0.02 \AA$ in the GS, and $R_{\mathrm{Nax}}=2.08 \pm 0.02 \AA$ and $R_{\mathrm{Neq}}=$ $2.17 \pm 0.02 \AA$ in the ES, which is in excellent agreement with $\sim 70$ ps-resolution synchrotron studies. ${ }^{29,30}$ The noise level of the transient difference is estimated from the point-to-point, i.e. high-frequency fluctuations and compared to the maximum of transient difference (at $\sim 7.125 \mathrm{keV}$ ), resulting in an estimated signal-to-noise ratio $(\mathrm{S} / \mathrm{N})$ of $\sim 500$. This is comparable to the one of previously published synchrotron EXAFS measurements using $\mathrm{MHz}$ repetition rate single photon counting TFY measurements, ${ }^{30,31}$ but about one order of magnitude lower than what can be achieved with novel multi-MHz high-dynamic-range setups. $^{42}$

\section{Femtosecond EXAFS measurements}

After establishing the feasibility of time-resolved EXAFS at LCLS, we performed femtosecond-resolved EXAFS measurements by continuously moving a delay stage in the optical pump arm over a range from -300 to $600 \mathrm{fs}$ while acquiring the XAS signal. The arrival time jitter is corrected using the timing tool ${ }^{43}$ and the data are binned on an incident X-ray energy and a pump-probe delay axis, forming a 2D intensity map of the transient intensity as shown in Fig. 4a (see also Fig. S7 for binned femtosecond XAS data as a function of X-ray energy, ESI $\dagger$ ). Cuts along the time axis 

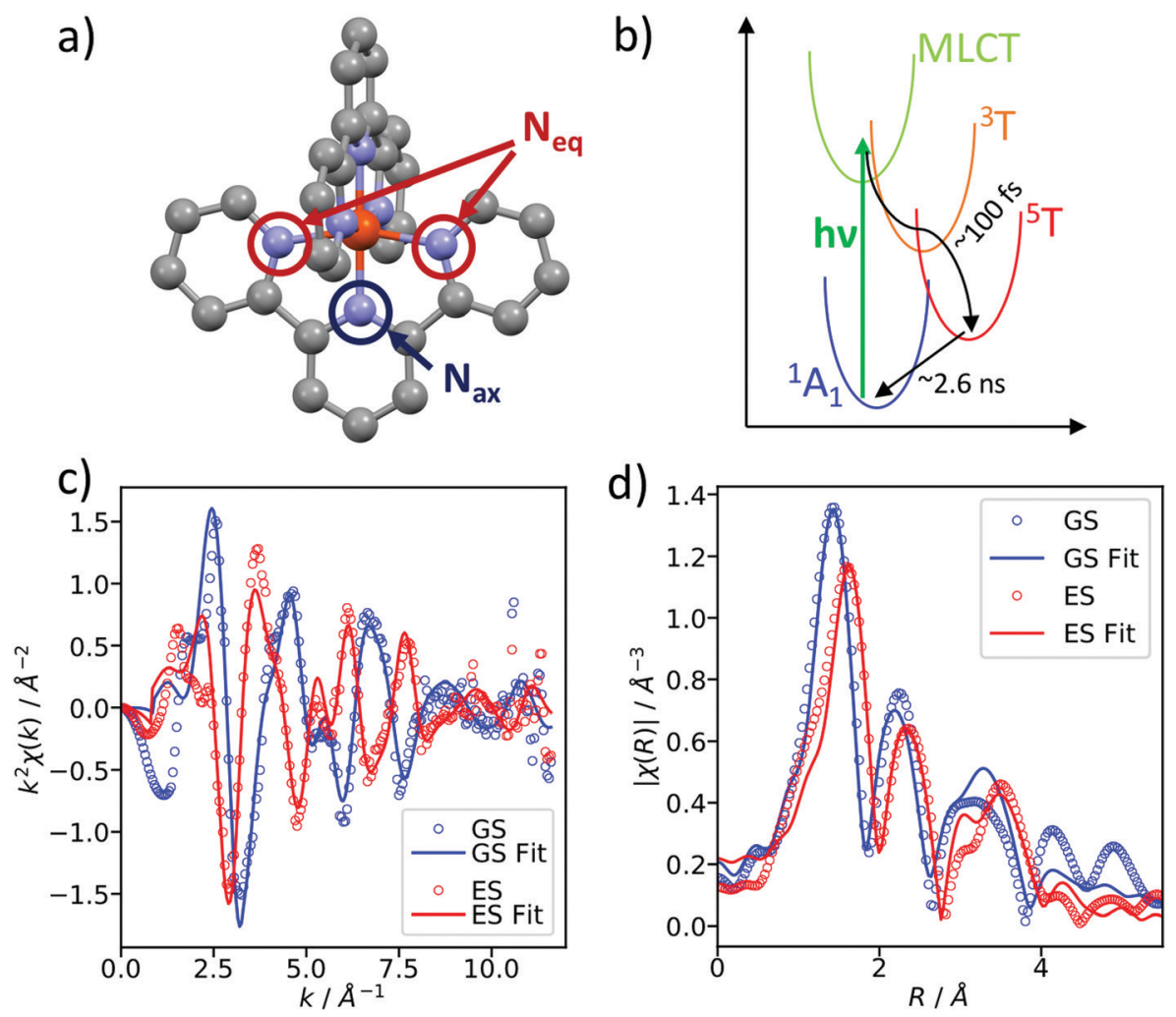

Fig. 3 (a) Due to the tridentate terpyridine ligands of $\left[\mathrm{Fe}(\text { terpy })_{2}\right]^{2+}$, the first coordination shell around Fe contains a total of $6 \mathrm{~N}$ atoms at two distinct distances, four equatorial $\left(N_{\text {eq }}\right)$ and two axial $\left(N_{\text {ax }}\right)$. (b) Schematic showing the potential energy surfaces which are involved in the ultrafast spin transition. (c) Background-subtracted measured EXAFS spectra and fit in $k$-space and (d) in $R$-space. The fit results in Fe-N bond length of $R_{\mathrm{Nax}}=1.86 \pm 0.02 \AA$ and $R_{\text {Neq }}=1.96 \pm 0.02 \AA$ in the GS as well as $R_{\text {Nax }}=2.08 \pm 0.02 \AA$ and $R_{\text {Neq }}=2.17 \pm 0.02 \AA$ in the ES.

of the 2D maps, e.g. at $7.156 \mathrm{keV}$, show coherent oscillations (Fig. 4b) analogous to a previous study on $\left[\mathrm{Fe}(\mathrm{bpy})_{3}\right]^{2+}{ }^{44}$ The detailed analysis of these oscillations is outside of scope of this paper, we merely show these as an indication of a temporal resolution $<100$ fs. The transient signals at $7135 \mathrm{eV}$ and $7158 \mathrm{eV}$ change their respective signs $200 \mathrm{fs}$ after optical excitation, and in the case of $\left[\mathrm{Fe}(\mathrm{bpy})_{3}\right]^{2+}$ these were found to be due to the crossing of a short-lived intermediate state. ${ }^{44}$ Using a kinetic model for the LS $\rightarrow$ IS $\rightarrow$ HS transition, in which we assume a Gaussian instrument response function of $70 \mathrm{fs}$ (FWHM), a lifetime of $100 \mathrm{fs}$ for the IS state, and neglecting the MLCT intermediate, we estimate that the average excited state population is $>50 \%$ in the IS state for the 0-200 fs range (see ESI $\dagger$ for further details). Accordingly, we re-bin the transient differences in the delay axis to obtain difference spectra for the delay bins 0-200 fs and $200-400$ fs and compare them to the 10 ps-difference spectrum from Fig. 2.

To visualize the general trend below the noise of the transient EXAFS spectra, we used a Savitzky-Golay filter ${ }^{45}$ with 11 point window size and third order polynomial (Fig. 4c). The difference spectra for $300 \pm 100$ fs and 10 ps are qualitatively identical, except for a decrease in amplitude at higher $k$ in the case of the $300 \mathrm{fs}$ spectrum. This amplitude difference is due to an increase in the Debye-Waller factor at time delays earlier than internal vibrational relaxation and energy dissipation to the solvent, which occur with time constants on the $\sim 1$ ps time scale for this class of materials. ${ }^{25}$ The resulting filtered spectra at $100 \pm 100$ fs and $300 \pm 100$ fs show a clear qualitative difference, which points towards the crossing of an intermediate state.

We simulated the EXAFS of the intermediate triplet and the long-lived quintet state in FEFF6 using the DFT structures from literature. ${ }^{41}$ To simulate the cold and thermally equilibrated IS state, the same EXAFS fit parameters obtained from the GS fit were used (Debye-Waller and amplitude reduction factors, energy shift, correction to the bond lengths). Additionally, to gain a better understanding of the observed amplitude reduction in the 300 fs-transient, we simulated a hot HS-LS difference (orange) by doubling the Debye-Waller factors compared to the cold HS-LS transient. The obtained simulated EXAFS transient for the cold HS-LS (green) difference is in good agreement with the $10 \mathrm{ps}$ data and the simulation reproduces the amplitude reduction characteristic for the hot HS state. While all $6 \mathrm{Fe}-\mathrm{N}$ bonds expand isotropically by $\sim 0.2 \AA$ in the HS state compared to the GS, in the IS state only the equatorial Fe- $\mathrm{N}$ bonds expand by $\sim 0.15 \AA$ and the axial ones stay contracted, resulting in an asymmetric, axially-compressed structure of the IS state with a significantly distinct EXAFS pattern. Most interestingly, the simulation of the IS-LS transient qualitatively resembles the relative trend visible in the 100 fs-data, which further indicates a crossing of the triplet IS state. The differences between the spectra of the IS and HS states are most 

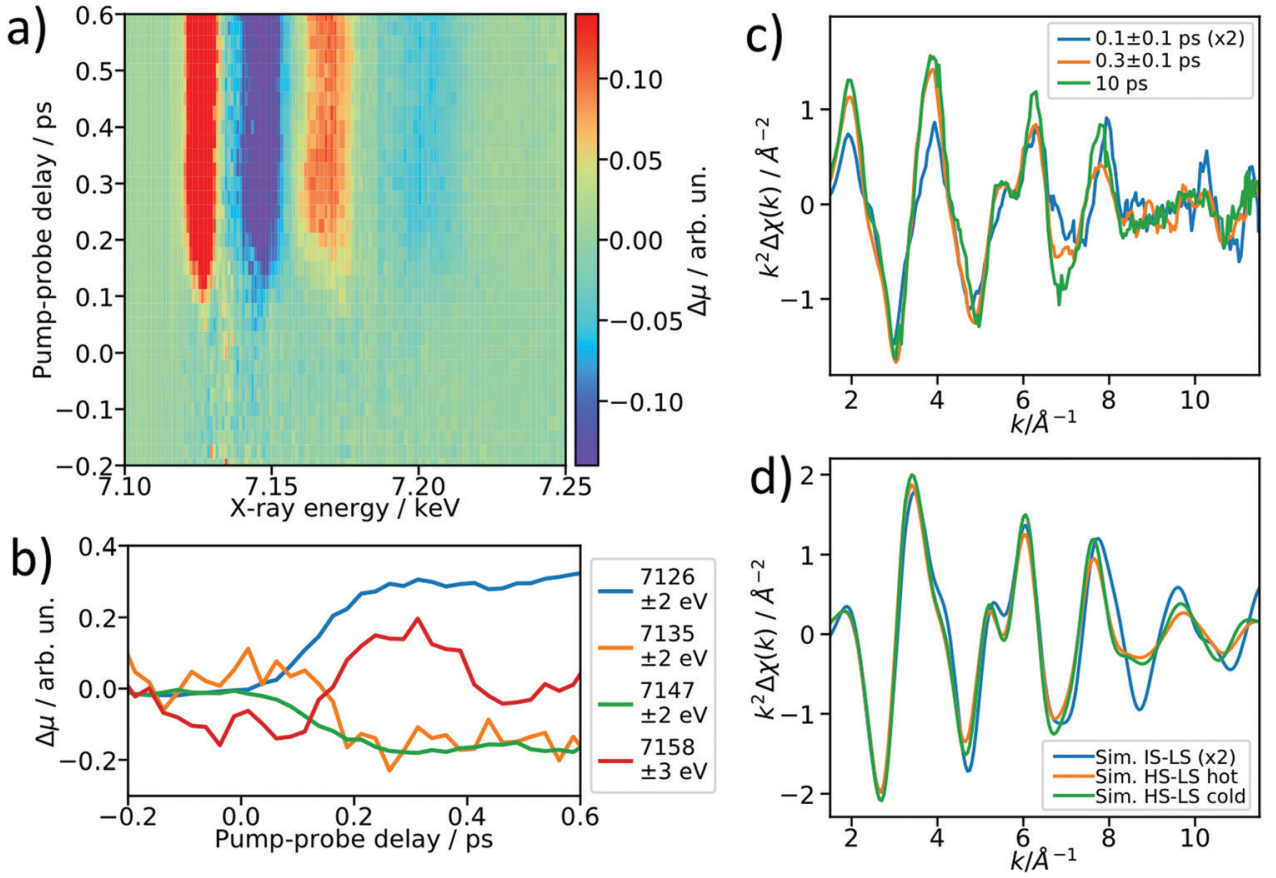

Fig. 4 Femtosecond resolved EXAFS measurement. (a) 2D false-color map showing the transient XAS intensity as a function of delay and energy. (b) Lineouts along the delay axis at selected energies, showing the $\sim 100 \mathrm{fs}$ temporal resolution of the experiment and coherent structural oscillations. (c) Re-binned and filtered 100 fs, 300 fs and 10 ps transient EXAFS spectra. (d) FEFF6 simulations of the triplet IS transient (IS-LS, blue), a "hot" (orange) and "cold" (green) HS transient qualitatively reproduce the measured EXAFS transient difference spectra.

pronounced in the $k$ region between $7-12 \AA^{-1}$, which stresses again the need to measure full EXAFS spectra up to several hundred $\mathrm{eV}$ above the absorption edge.

\section{Discussion and outlook}

In conclusion, we have demonstrated the viability of timeresolved EXAFS with $\sim 100$ fs resolution using fixed gap undulators at LCLS. The benchmark experiments on a $20 \mathrm{mM}$ solution of $\left[\mathrm{Fe}(\text { terpy })_{2}\right]^{2+}$ in a $50 \mu \mathrm{m}$ jet show a comparable $\mathrm{S} / \mathrm{N}$ to synchrotron time-resolved measurements with $\sim 70$ ps resolution. Furthermore, we have shown that femtosecond EXAFS can be used to track structural changes of a short-lived ( $\sim 100 \mathrm{fs})$ intermediate spin state in the optically induced low- to highspin transition.

In the future, we envisage combining these measurements with simultaneous ultrafast dispersive $\mathrm{XES}^{46}$ when the incident beam is at the high energy part of the EXAFS spectrum. In the aforementioned spin-transition example, the XES K $\beta$ fingerprints can then be used to quantitatively disentangle the EXAFS of the intermediate spin state species. The EXAFS spectrum can then be thoroughly analyzed in $R$-space and the structure of the 100 fs-lived intermediate can be determined. Such capabilities will be especially compelling at XFELs with variable gap undulators, such as the upgraded LCLS-II ${ }^{47}$ and the high-repetition rate European XFEL. ${ }^{48}$ The variable gap undulator will ease the incident $\mathrm{X}$-ray energy scanning and the high repetition rate will increase the average flux by $2-3$ orders of magnitude. These light sources will enable EXAFS measurements of traditionally challenging samples with low concentration or weak transient changes, which are particularly interesting for chemistry, materials science, and biology.

\section{Author contributions}

$\mathrm{AB}, \mathrm{DS}$ and RAM designed the research; all authors conducted the X-ray experiments at the LCLS; AB analyzed the data. The manuscript was written by AB, DS and RAM, with contributions from all authors.

\section{Conflicts of interest}

There are no conflicts to declare.

\section{Acknowledgements}

This work was supported by the Computational Materials Sciences Program funded by the U.S. Department of Energy, Office of Science, Basic Energy Sciences, under Award No. DE-SC0014607. Use of the Linac Coherent Light Source (LCLS), SLAC National Accelerator Laboratory, are supported by the U.S. Department of Energy, Office of Science, Office of Basic Energy Sciences under Contract No. DE-AC02-76SF00515. AB thanks Amy Cordones-Hahn for her support in characterizing the synthesized $\left[\mathrm{Fe}(\text { terpy })_{2}\right]^{2+}$ and Clemens Weninger for his support with data processing. 


\section{References}

1 J. C. Kendrew, R. E. Dickerson, B. E. Strandberg, R. G. Hart, D. R. Davies, D. C. Phillips and V. C. Shore, Nature, 1960, 185, 422-427.

2 K. N. Ferreira, T. M. Iverson, K. Maghlaoui, J. Barber and S. Iwata, Science, 2004, 303, 1831.

3 J. I. Goldsmith, W. R. Hudson, M. S. Lowry, T. H. Anderson and S. Bernhard, J. Am. Chem. Soc., 2005, 127, 7502-7510.

4 M. Grätzel, Inorg. Chem., 2005, 44, 6841-6851.

5 T. J. Penfold, J. Szlachetko, F. G. Santomauro, A. Britz, W. Gawelda, G. Doumy, A. M. March, S. H. Southworth, J. Rittmann, R. Abela, M. Chergui and C. J. Milne, Nat. Commun., 2018, 9, 1-9.

6 Y. Obara, H. Ito, T. Ito, N. Kurahashi, S. Thürmer, H. Tanaka, T. Katayama, T. Togashi, S. Owada, Y. I. Yamamoto, S. Karashima, J. Nishitani, M. Yabashi, T. Suzuki and K. Misawa, Struct. Dyn., 2017, 4, 044033.

7 J. Wong, F. W. Lytle, R. P. Messmer and D. H. Maylotte, Phys. Rev. B: Condens. Matter Mater. Phys., 1984, 30, 5596-5610.

8 T. E. Westre, P. Kennepohl, J. G. Dewitt, B. Hedman, K. O. Hodgson and E. I. Solomon, J. Am. Chem. Soc., 1997, 119, 6297-6314.

9 M. Benfatto, S. D. Longa and C. R. Natoli, J. Synchrotron Radiat., 2003, 10, 51-57.

10 D. E. Sayers, E. A. Stern and F. Lytle, J. Phys. Chem. Lett., 1971, 27, 1204.

11 D. C. Koningsberger, B. L. Mojet, G. E. van Dorssen and D. E. Ramaker, Top. Catal., 2000, 10, 143-155.

12 J. J. Rehr and R. C. Albers, Rev. Mod. Phys., 2000, 72, 621-654.

13 P. Emma, R. Akre, J. Arthur, R. Bionta, C. Bostedt, J. Bozek, A. Brachmann, P. Bucksbaum, R. Coffee, F.-J. Decker, Y. Ding, D. Dowell, S. Edstrom, A. Fisher, J. Frisch, S. Gilevich, J. Hastings, G. Hays, P. Hering, Z. Huang, R. Iverson, H. Loos, M. Messerschmidt, A. Miahnahri, S. Moeller, H.-D. Nuhn, G. Pile, D. Ratner, J. Rzepiela, D. Schultz, T. Smith, P. Stefan, H. Tompkins, J. Turner, J. Welch, W. White, J. Wu, G. Yocky and J. Galayda, Nat. Photonics, 2010, 4, 641-647.

14 M. Kubin, J. Kern, S. Gul, T. Kroll, R. Chatterjee, H. Löchel, F. D. Fuller, R. G. Sierra, W. Quevedo, C. Weniger, J. Rehanek, A. Firsov, H. Laksmono, C. Weninger, R. Alonso-mori, D. L. Nordlund, B. Lassalle-kaiser, J. M. Glownia, J. Krzywinski, S. Moeller, J. J. Turner, M. P. Minitti, G. L. Dakovski, S. Koroidov, A. Kawde, J. S. Kanady, E. Y. Tsui, S. Suseno, Z. Han, E. Hill, T. Taguchi, S. Andrew, T. Agapie, J. Messinger, A. Erko, A. Föhlisch, U. Bergmann, R. Mitzner, V. K. Yachandra, J. Yano, P. Wernet, M. Kubin, J. Kern, S. Gul, T. Kroll, F. D. Fuller, R. G. Sierra, W. Quevedo, C. Weniger, J. Rehanek, A. Firsov, H. Laksmono, C. Weninger, R. Alonso-mori, D. L. Nordlund, B. Lassallekaiser, J. M. Glownia, J. Krzywinski, S. Moeller, J. J. Turner, M. P. Minitti, G. L. Dakovski, S. Koroidov, A. Kawde and J. S. Kanady, Struct. Dyn., 2017, 4, 054307.

15 R. Neutze, R. Wouts, D. Van Der Spoel and E. Weckert, Nature, 2000, 406, 752-757.
16 H. T. Lemke, C. Bressler, L. X. Chen, D. M. Fritz, K. J. Gaffney, A. Galler, W. Gawelda, K. Haldrup, R. W. Hartsock, H. Ihee, J. Kim, K. H. Kim, J. H. Lee, M. M. Nielsen, A. B. Stickrath, W. Zhang, D. Zhu and M. Cammarata, J. Phys. Chem. A, 2013, 117, 735-740.

17 M. Cammarata, R. Bertoni, M. Lorenc, H. Cailleau, S. Di Matteo, C. Mauriac, S. F. Matar, H. Lemke, M. Chollet, S. Ravy, C. Laulhé, J. F. Létard and E. Collet, Phys. Rev. Lett., 2014, 113, 227402.

18 M. Levantino, H. T. Lemke, G. Schirò, M. Glownia, A. Cupane and M. Cammarata, Struct. Dyn., 2015, 2, 041713.

19 N. A. Miller, A. Deb, R. Alonso-Mori, B. D. Garabato, J. M. Glownia, L. M. Kiefer, J. Koralek, M. Sikorski, K. G. Spears, T. E. Wiley, D. Zhu, P. M. Kozlowski, K. J. Kubarych, J. E. Penner-Hahn and R. J. Sension, J. Am. Chem. Soc., 2017, 139, 1894-1899.

20 N. A. Miller, A. Deb, R. Alonso-Mori, J. M. Glownia, L. M. Kiefer, A. Konar, L. B. Michocki, M. Sikorski, D. L. Sofferman, S. Song, M. J. Toda, T. E. Wiley, D. Zhu, P. M. Kozlowski, K. J. Kubarych, J. E. Penner-Hahn and R. J. Sension, J. Phys. Chem. A, 2018, 122, 4963-4971.

21 M. L. Shelby, P. J. Lestrange, N. E. Jackson, K. Haldrup, M. W. Mara, A. B. Stickrath, D. Zhu, H. T. Lemke, M. Chollet, B. M. Hoffman, X. Li and L. X. Chen, J. Am. Chem. Soc., 2016, 138, 8752-8764.

22 M. W. Mara, R. G. Hadt, M. E. Reinhard, T. Kroll, H. Lim, R. W. Hartsock, R. Alonso-Mori, M. Chollet, J. M. Glownia, S. Nelson, D. Sokaras, K. Kunnus, K. O. Hodgson, B. Hedman, U. Bergmann, K. J. Gaffney and E. I. Solomon, Science, 2017, 356, 1276-1280.

23 E. Biasin, T. B. Van Driel, K. S. Kjær, A. O. Dohn, M. Christensen, T. Harlang, P. Chabera, Y. Liu, J. Uhlig, M. Pápai, Z. Németh, R. Hartsock, W. Liang, J. Zhang, R. Alonso-mori, M. Chollet, J. M. Glownia, S. Nelson, D. Sokaras, T. A. Assefa, A. Britz, A. Galler, W. Gawelda, C. Bressler, K. J. Gaffney, H. T. Lemke, K. B. Møller, M. M. Nielsen, V. Sundström, G. Vankó, K. Wärnmark, S. Canton and K. Haldrup, Phys. Rev. Lett., 2016, 117, 013002.

24 E. Biasin, T. B. van Driel, G. Levi, M. G. Laursen, A. O. Dohn, A. Moltke, P. Vester, F. B. K. Hansen, K. S. Kjaer, T. Harlang, R. Hartsock, M. Christensen, K. J. Gaffney, N. E. Henriksen, K. B. Møller, K. Haldrupa and M. M. Nielsen, J. Synchrotron Radiat., 2018, 25, 306-315.

25 K. Haldrup, W. Gawelda, R. Abela, R. Alonso-Mori, U. Bergmann, A. Bordage, M. Cammarata, S. E. Canton, A. O. Dohn, T. B. van Driel, D. M. Fritz, A. Galler, P. Glatzel, T. Harlang, K. S. Kjær, H. T. Lemke, K. B. Møller, Z. Németh, M. Pápai, N. Sas, J. Uhlig, D. Zhu, G. Vankó, V. Sundström, M. M. Nielsen and C. Bressler, J. Phys. Chem. B, 2016, 120, 1158-1168.

26 D. Rimmerman, D. Leshchev, D. J. Hsu, J. Hong, B. Abraham, R. Henning, I. Kosheleva and L. X. Chen, J. Phys. Chem. B, 2018, 122, 5218-5224.

27 X. Zhang, S. E. Canton, G. Smolentsev, C. Wallentin, Y. Liu, Q. Kong, K. Attenkofer, A. B. Stickrath, M. W. Mara, 
L. X. Chen, K. Wärnmark and V. Sundström, J. Am. Chem. Soc., 2014, 136, 8804-8809.

28 S. E. Canton, X. Zhang, M. L. Lawson Daku, A. L. Smeigh, J. Zhang, Y. Liu, C. Wallentin, K. Attenkofer, G. Jennings, C. A. Kurtz, D. Gosztola, A. Hauser and V. Sundström, J. Phys. Chem. C, 2014, 118, 4536.

29 X. Zhang, M. L. Lawson Daku, J. Zhang, K. Suarez-Alcantara, G. Jennings, C. A. Kurtz and S. E. Canton, J. Phys. Chem. C, 2015, 119, 3312-3321.

30 G. Vankó, A. Bordage, M. Pápai, K. Haldrup, P. Glatzel, A. M. March, G. Doumy, A. Britz, A. Galler, T. A. Assefa, D. Cabaret, T. B. Van Driel, K. S. Kjær, A. O. Dohn, K. B. Moller, H. T. Lemke, M. Rovezzi, Z. Németh, E. Rozsályi, T. Rozgonyi, J. Uhlig, V. Sundstrom, M. M. Nielsen, L. Young, S. H. Southworth, C. Bressler and W. Gawelda, J. Phys. Chem. C, 2015, 119, 5888-5902.

31 A. Britz, W. Gawelda, T. A. Assefa, L. L. Jamula, J. T. Yarranton, A. Galler, D. Khakhulin, M. Diez, M. Harder, G. Doumy, A. M. March, É. Bajnóczi, Z. Németh, M. Pápai, E. Rozsályi, D. S. Szemes, H. Cho, S. Mukherjee, C. Liu, T. K. Kim, R. W. Schoenlein, S. H. Southworth, L. Young, E. Jakubikova, N. Huse, G. Vankó, C. Bressler and J. K. McCusker, Inorg. Chem., DOI: 10.1021/acs.inorgchem.9b01063.

32 J. Zhang, X. Zhang, K. Suarez-alcantara, G. Jennings, C. A. Kurtz, L. Daku and S. E. Canton, ACS Omega, 2019, 4, 6375-6381.

33 C. Bressler, C. J. Milne, V.-T. Pham, A. ElNahhas, R. M. van der Veen, W. Gawelda, S. L. Johnson, P. Beaud, D. Grolimund, M. Kaiser, C. N. Borca, G. Ingold, R. Abela and M. Chergui, Science, 2009, 323, 489-492.

34 J. Weisshaupt, V. Juvé, M. Holtz, S. Ku, M. Woerner, T. Elsaesser, S. Ališauskas, A. Pugžlys and A. Baltuška, Nat. Photonics, 2014, 8, 927-930.

35 R. Chatterjee, C. Weninger, A. Loukianov, S. Gul, F. D. Fuller, M. H. Cheah, T. Fransson, S. Nelson, S. Song, A. Britz, J. Messinger, U. Bergmann, R. Alonso-Mori, V. K. Yachandra, J. Kern and J. Yano, J. Synchrotron Radiat., DOI: $10.1107 / \mathrm{S} 1600577519007550$.

36 M. Chollet, R. Alonso-Mori, M. Cammarata, D. Damiani, J. Defever, J. T. Delor, Y. Feng, J. M. Glownia, J. B. Langton, S. Nelson, K. Ramsey, A. Robert, M. Sikorski, S. Song,
D. Stefanescu, V. Srinivasan, D. Zhu, H. T. Lemke and D. M. Fritz, J. Synchrotron Radiat., 2015, 22, 503-507.

37 S. Narayanan, A. Sandy, D. Shu, M. Sprung, C. Preissner and J. Sullivan, J. Synchrotron Radiat., 2008, 15, 12-18.

38 G. Blaj, P. Caragiulo, G. Carini, S. Carron, A. Dragone, D. Freytag, G. Haller, P. Hart, J. Hasi, R. Herbst, S. Herrmann, C. Kenney, B. Markovic, K. Nishimura, S. Osier, J. Pines, B. Reese, J. Segal, A. Tomada and M. Weaver, J. Synchrotron Radiat., 2015, 22, 577-583.

39 W. Zhang, R. Alonso-Mori, U. Bergmann, C. Bressler, M. Chollet, A. Galler, W. Gawelda, R. G. Hadt, R. W. Hartsock, T. Kroll, K. S. Kjær, K. Kubiček, H. T. Lemke, H. W. Liang, D. A. Meyer, M. M. Nielsen, C. Purser, J. S. Robinson, E. I. Solomon, Z. Sun, D. Sokaras, T. B. van Driel, G. Vankó, T.-C. Weng, D. Zhu and K. J. Gaffney, Nature, 2014, 509, 345-348.

40 B. Ravel and M. Newville, J. Synchrotron Radiat., 2005, 12, 537-541.

41 D. N. Bowman, A. Bondarev, S. Mukherjee and E. Jakubikova, Inorg. Chem., 2015, 54, 8786-8793.

42 A. Britz, T. A. Assefa, A. Galler, W. Gawelda, M. Diez, P. Zalden, D. Khakhulin, B. Fernandes, P. Gessler, H. S. Namina, A. Beckmann, M. Harder, H. Yavaş and C. Bressler, J. Synchrotron Radiat., 2016, 23, 1-15.

43 M. Harmand, R. Coffee, M. R. Bionta, M. Chollet, D. French, D. Zhu, D. M. Fritz, H. T. Lemke, N. Medvedev, B. Ziaja, S. Toleikis and M. Cammarata, Nat. Photonics, 2013, 7, 215-218.

44 H. T. Lemke, K. S. Kjær, R. Hartsock, T. B. van Driel, M. Chollet, J. M. Glownia, S. Song, D. Zhu, E. Pace, S. F. Matar, M. M. Nielsen, M. Benfatto, K. J. Gaffney, E. Collet and M. Cammarata, Nat. Commun., 2017, 8, 15342. 45 A. Savitzky and M. J. E. Golay, Anal. Chem., 1964, 36, 1627-1639. 46 R. Alonso-Mori, J. Kern, D. Sokaras, T. C. Weng, D. Nordlund,

R. Tran, P. Montanez, J. Delor, V. K. Yachandra, J. Yano and U. Bergmann, Rev. Sci. Instrum., 2012, 83, 073114.

47 https://lcls.slac.stanford.edu/lcls-ii (accessed June 13, 2019). 48 T. Tschentscher, C. Bressler, J. Grünert, A. Madsen, A. P. Mancuso, M. Meyer, A. Scherz, H. Sinn and U. Zastrau, Appl. Sci., 2017, 7, 1-35. 